\title{
BENDING BEHAVIOUR OF GLULAM BEAMS REINFORCED WITH CARBON FRP PLATES
}

\author{
Ivan GLIŠOVIĆ, Boško STEVANOVIĆ, Miloš PETROVIĆ \\ Faculty of Civil Engineering, University of Belgrade, Bulevar Kralja Aleksandra 73/I, 11000 Belgrade, Serbia
}

Received 28 Nov 2012; accepted 27 Feb 2013

\begin{abstract}
The idea of reinforcing glued laminated timber (glulam) beams came in response to the need to improve the mechanical properties, as well as to ensure higher reliability of this type of structural elements. This paper describes an experimental program which examines the reinforcement in flexure of glulam beams with carbon fibre reinforced plastic (CFRP) plates. Fifteen beams reinforced with CFRP at the tension side and five unreinforced control beams were instrumented and tested to failure in a four-point bending configuration. The mechanical properties of reinforced beams are compared to those of unreinforced beams with regard to the load-deflection behaviour, failure mode, ultimate load capacity, stiffness and strain distribution. The experimental results demonstrated the beneficial effect of the proposed reinforcing solution in terms of strength, stiffness and ductility.
\end{abstract}

Keywords: glulam beams, carbon fibres, reinforcement, bending tests.

\section{Introduction}

Timber has been used as a building material from the earliest times. Even today, in addition to progress of steel and concrete, timber structures have their own special place in the modern construction industry. Lightweight and relatively high strength, workability, easy of handling and assembly, attractive aesthetic appearance and environmental compatibility are only some of the parameters which effect the successful application of timber structures. However, timber also has a number of disadvantages. Variability in terms of strength and stiffness of wood, caused by the presence of natural defect and variations in growth conditions, make it difficult to predict the behaviour of timber elements at different loads (Jacob, Barragan 2010). These problems can be solved with the development of wood-based products by gluing smaller pieces of solid timber such as glued laminated timber (glulam). This technique allows the production of timber elements in which the defects are dispersed, ensuring a final product with more uniform properties, whose dimensions are theoretically unlimited (Juvandes, Barbosa 2012). Capable of spanning greater lengths and carrying greater loads, glulam has advanced the timber as a building material. Although glulam offers significant improvement over sawn timber, its ultimate bending strength often remains limited by strength reducing flaws, such as knots and finger joints, in the tension zone. Tension failure mode is brittle as the timber does not exhibit plastic behaviour under tensile loads. This can even lead to cracks along the timber grain, which will result in terrible destruction of the cross section.

When a timber beam is reinforced at a tension zone, the failure mode for the timber structures may change from tension failure to compressive failure, which is more ductile. In other words, this method increases the tensile capacity of the beam, meaning that the compressive capacity of a timber is utilized at its fullest (Yusof 2010). As a result, it can be applied in a new construction, as well as in the rehabilitation of existing timber structures. Effective techniques for reinforcing timber can be used to reduce the size of beams and allow for utilization of lower grades of wood, creating a more efficient use of timber supply. The same strengthening techniques may be used in order to increase the loadcarrying capacity of existing timber elements, so that the same elements could support much higher loads when compared to those in the original design of the structure, thus saving money and material needed to replace the structure (Gentile 2000).

Tensile reinforcement of glulam beams was researched in the past, most commonly by using metal reinforcement (steel plates or bars, aluminium plates). Such a conventional reinforcement method is simple and efficient, but is with certain drawbacks such as increased dead loads, difficulty in transportation and installation, and maintenance costs. In addition, steel components are prone to corrosion, and aluminium plates may buckle when thermal loads are occurred. 
In recent years, the increased availability and a reduced cost of fibre reinforced polymer (FRP) materials have aroused interest in research into reinforcing timber structures. Fibre reinforced polymers are a relatively new class of composite materials manufactured from artificial fibres and resins. The three fibre types most commonly used in structural applications are glass, carbon and aramid. High stiffness and tensile strength, low weight, easy installation, high durability (no corrosion), electromagnetic permeability, and practically unlimited availability in terms of geometry and size are the main advantages of these composites (ACI 440.2R-08:2008). In addition, these materials can be manufactured in factory controlled environments to very precise tolerances in relation to their mechanical properties (Raftery, Harte 2011). FRPs have many important advantages over steel when the same are considered as a reinforcing material for timber. The heat conductivity of the FRP composites is much lower than that of steel whereby the structure is more fire resistant (Jankowski et al. 2010). Moreover, the FRP materials and wood are more compatible owing to their similar thermal expansion (Issa, Kmeid 2005). The compatibility of a timber and FRP composites in terms of strains at failure is also an important issue, critical to the full utilization of timber strength. The behaviour in a linear elastic manner and high strain capacity of FRP reinforcement allow tension laminates to reach their ultimate tensile capacity, and timber compression fibres to reach their yield strains. On the other hand, where steel is used as the reinforcing material the timber will not reach its full strain capacity prior to the yielding of the reinforcement (Gilfillan et al. 2003).

A number of research studies have examined the attractive option of reinforcing timber flexural members with fibre reinforced polymer plates. Much effort was expended to study the short-term response of timberFRP plates (Hernandez et al. 1997; Blaß, Romani 2000; Johns, Lacroix 2000; Fiorelli, Dias 2003, 2006, 2011; Gilfillan et al. 2003; Borri et al. 2005; Issa, Kmeid 2005; Schober, Rautenstrauch 2006; Li et al. 2009; Jankowski et al. 2010; Jacob, Barragan 2010; Yusof 2010; Raftery, Harte 2011), the interaction and bond strength of FRP-timber interface (Raftery et al. 2009; Juvandes, Barbosa 2012), as well as the long-term performance of FRP reinforced timber members (Gilfillan et al. 2003; Yahyaei-Moayyed, Taheri 2011). As a result, all of these researchers concluded that the addition of FRP in the tension zone of flexural members may improve the strength, stiffness and ductility of beams, and possibly lower the mechanical variability of beams when compared to unreinforced ones.

The main purpose of this paper is to study the shortterm behaviour of glulam beams with flexural reinforcement by using carbon fibre reinforced polymers (CFRP) plates. Bending behaviour of CFRP-reinforced beams was compared with unreinforced beams that were used as control specimens. All beams were tested to failure under four-bending configuration. Experimental results are presented in terms of load-deflection relationship, failure mode, ultimate load capacity, stiffness and strain distribution.

\section{Materials}

\subsection{Glulam}

Glulam was manufactured from Spruce (Picea abies) timber, of strength class C24 (EN 338 2009). The timber came from the same stand in order to minimize the influence of the variability in timber properties. The timber stock was initially kiln dried until reaching $18 \%$ of moisture content and then conditioned for three months at the relative humidity of $65 \pm 5 \%$ and at the temperature of $20 \pm 2{ }^{\circ} \mathrm{C}$. An approximate equilibrium moisture content of $12 \%$ was obtained after the conditioning period, and a mean timber density of $427 \mathrm{~kg} / \mathrm{m}^{3}$ was recorded. The average mechanical properties, obtained from preliminary testing compliant with EN 408 (2010), are reported in Table 1.

Table 1. Experimental mechanical properties of Spruce timber

\begin{tabular}{lc}
\hline \multicolumn{1}{c}{ Property } & Value \\
\hline Tensile strength parallel to grain (MPa) & 27.8 \\
\hline Compression strength parallel to grain $(\mathrm{MPa})$ & 36.2 \\
\hline Bending strength $(\mathrm{MPa})$ & 42.5 \\
\hline Modulus of elasticity parallel to grain $(\mathrm{MPa})$ & 11080 \\
\hline
\end{tabular}

Each glued laminated timber beam was obtained by assembling 7 laminations which are $80 \mathrm{~mm}$ wide, $30 \mathrm{~mm}$ thick and $4000 \mathrm{~mm}$ long. The requested size of glulam beams was $80 \times 210 \times 4000 \mathrm{~mm}$. Laminations of better quality (fewer critical strength reducing defects such as knots, fissures and grain deviation) were placed on the region of the greatest stress. A phenol-resorcinol adhesive was used to glue laminations into the monolith section, where the bonding performed under pressure of 0.5 to $0.8 \mathrm{MPa}$ for the period of $12 \mathrm{~h}$ at the temperature of approximately $20^{\circ} \mathrm{C}$.

\subsection{Fibre reinforced polymer}

Fibre reinforced polymer is an advanced composite material which consists of many thin and long fibres embedded in a polymer resin matrix. Fibres provide both load carrying capacity and stiffness to the composite, while the matrix is necessary to hold fibres together and ensure the load among fibers. In addition, polymer matrix protects fibres from the environment and allows adhesive to be placed on fibres in an arbitrary fashion ( $\mathrm{Li}$ et al. 2009). Composite materials for structural strengthening are available today typically in the form of plates, sheets or bars.

FRP material used in the test program comprised carbon fibres in an epoxy matrix. Carbon fibres are much more expensive than glass fibres, but have significantly higher mechanical, thermal and chemical properties (An- 
dre 2006). The carbon fibre plates were obtained from Sika Group, a company that has extensive experience in terms of repairing and strengthening of reinforced concrete and masonry structures. The plates used for this research were Sika CarboDur S613 with cross sectional dimension $60 \times 1.3 \mathrm{~mm}$. Sika CarboDur is a pultruded carbon fibre reinforced polymer plate designed for the purpose of strengthening concrete, timber and masonry structures. The plates consisted of unidirectional fibres aligned along the longitudinal direction with fibre volume content greater then $68 \%$. The density of this reinforcement is $1.6 \mathrm{~g} / \mathrm{cm}^{3}$.

Ten samples from CFRP plate were tested in tension with reference to EN 527-5 (2009) in order to determine its ultimate strength, ultimate strain and modulus of elasticity. Table 2 shows mechanical properties of the CFRP reinforcement. The experimental results for modulus of elasticity, tensile strength and strain at failure are close to the value specified by the manufacturer (Sika Group 2011a).

Table 2. Summary of results for tensile test of CFRP plates

\begin{tabular}{lc}
\hline \multicolumn{1}{c}{ Property } & Value \\
\hline Experimental results (average) & \\
\hline Tensile strength (MPa) & 2846 \\
\hline Modulus of elasticity (MPa) & 165543 \\
\hline Maximum strain (\%) & 1.79 \\
\hline Provided by Sika & 2800 \\
\hline Tensile strength (MPa) & 165000 \\
\hline Modulus of elasticity (MPa) & 1.7 \\
\hline Maximum strain (\%)
\end{tabular}

\subsection{Adhesive}

Epoxy adhesives are well established in civil engineering and it is reported that they are generally considered to be the most suitable for the bonding of composite materials. They have certain advantages such as good gap-filling characteristics, limited shrinkage during curing, ability to achieve full cure at ambient temperatures, and only require low clamping pressures (Raftery et al. 2009). Consequently, epoxy adhesives are often employed in CFRP-timber bonded connections in the reinforcing timber members.

The adhesive used to bond glulam beams and CFRP plates was Sikadur-30, which is a Sika produce. Advantages of this resin are the relative low cost and no odors' emissions during its application. Sikadur-30 is solvent free adhesive based on a combination of epoxy resin and special filler, which is used primarily to bond structural reinforcements to other substrates. It consists of component A (Resin) and B (Hardener). Sikadur-30 is ready to be used when mixing these two components in ratio A: $\mathrm{B}=3: 1$, either by weight or volume. Table 3 shows the mechanical properties of adhesive provided by the manufacturer (Sika Group 2011b).
Table 3. Typical data of mechanical properties of epoxy resin (Curing conditions: $23{ }^{\circ} \mathrm{C}$ and $50 \%$ R.H.)

\begin{tabular}{lc}
\hline \multicolumn{1}{c}{ Property } & Value \\
\hline Tensile strength after 7 days $(\mathrm{MPa})$ & 24.8 \\
\hline Elongation at break $(\%)$ & 1.0 \\
\hline Compression strength after 7 days $(\mathrm{MPa})$ & 59.3 \\
\hline Bending strength after 14 days $(\mathrm{MPa})$ & 46.8 \\
\hline Modulus of elasticity in bending after 14 days $(\mathrm{MPa})$ & 11721 \\
\hline
\end{tabular}

\section{Experimental method}

\subsection{Test program}

The experimental investigation was carried out at the Material Testing Laboratory of the Faculty of Civil Engineering, University of Belgrade. The test program involved the fabrication of reinforced glulam beams and testing to failure of both unreinforced and reinforced beams under four-point bending. The results for the unreinforced beams are reported solely for the purpose of quantitatively evaluating the effectiveness of the intervention by making comparison with those results of reinforced beams.

Information relating to all test series is given in Table 4.

Table 4. Test program

\begin{tabular}{cccc}
\hline Series & Arrangement & $\begin{array}{c}\text { Reinforcement } \\
\text { ratio (\%) }\end{array}$ & $\begin{array}{c}\text { Number of } \\
\text { specimens }\end{array}$ \\
\hline A & Unreinforced & 0 & 5 \\
\hline B & Reinforced & 0.46 & 10 \\
\hline C & Reinforced & 0.93 & 5 \\
\hline
\end{tabular}

Arrangement of the reinforcement was as follows:

- A - no reinforcement;

- B - one $60 \times 1.3 \times 3600 \mathrm{~mm}$ CFRP plate bonded centrally to the tension zone of the glulam beam;

- C - two $60 \times 1.3 \times 3600 \mathrm{~mm}$ CFRP plates bonded centrally to the tension zone of the glulam beam.

\subsection{Reinforced beam fabrication}

In the fabrication of reinforced beams, the substrate had to be made first before the composite plates were bonded to tensile face of glulam beams. The timber surface was prepared as suggested in the manufacturer's instructions so that CFRP plates and timber could be properly bonded. To eliminate splinters and dust, a sanding process with sandpaper was applied at those zones where CFRP's systems were planned to be installed, followed by the application of compressed air. CFRP plates were cut to the desired length, and were cleaned properly with acetone (Sika Colma Cleaner) so as to remove any contaminant. Well-mixed Sikadur-30 was applied by using a special "roof-shaped" spatula over the cleaned carbon plate to nominal thickness of $1 \mathrm{~mm}$. The epoxy adhesive was applied over the cleaned and prepared substrate with a trowel to a thickness of approximately $1 \mathrm{~mm}$. Within the open time of the epoxy, the CFRP plate was placed 


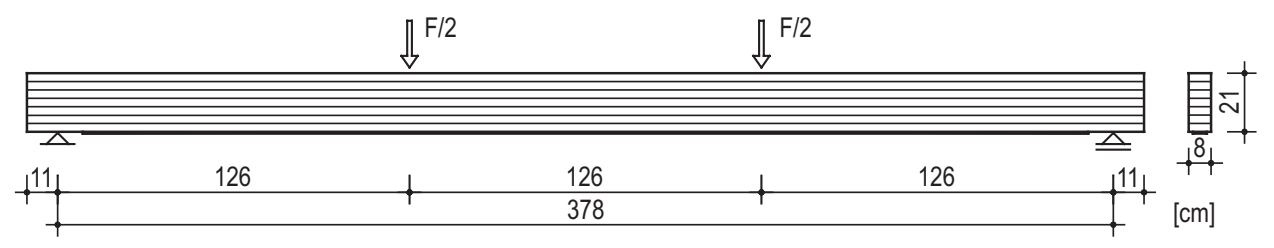

Fig. 1. Bending test configuration

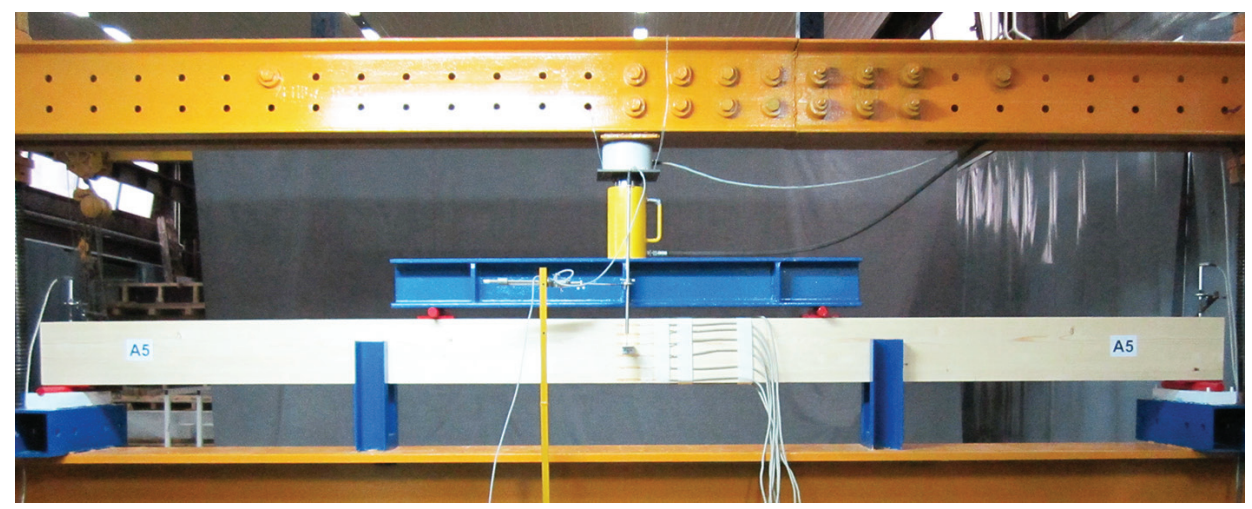

Fig. 2. Test set-up

onto the glulam surface. The composites plate was attached starting at one end and applying enough pressure by rubber roller to press out any excess epoxy from the sides of the plate. All excess epoxy was removed from the sides of the CFRP plate. To ensure a proper bonding, the specimens were cured for seven days at room temperature of $20 \pm 2{ }^{\circ} \mathrm{C}$.

A two-step process was used for five beams with two layers of CFRP at the tension side. One CFRP plate was bonded to the glulam beam, as previously described; then the next CFRP plate was bonded with the same epoxy adhesive. After the first CFRP layer was glued to the glulam beam, the epoxy adhesive was applied only onto the second layer, which was placed on already attached CFRP layer.

\subsection{Beam testing}

All beams (Series A-C) were subjected to bending test in accordance with EN 408 (2010). The beams were tested to failure under monotonic load in four-point bending configuration with a simple supported span of 3780 $\mathrm{mm}$ (18 times the beams' depth). The two load points were at a distance from their reaction equal to one third of the span. The loading was done by using a loading cell, whose maximum capacity of $250 \mathrm{kN}$, powered by $350 \mathrm{kN}$ hydraulic jacks. In the test procedure, the load was transformed from one load point to two load points by using the steel beam. The test specimens were simply supported on roller bearings. In addition, roller bearings were used at the load application points to ensure pure vertical loading and to provide moment free loading. Steel plates were placed beneath the two load points, as well as at the supports, so that local indentations would be minimized. Lateral restraints were provided to prevent lateral buckling of the beams. A schematic representation of the test configuration is shown in Figure 1, whereas typical testing setup for the beams is shown in Figure 2.

The deflections of the beams were measured by using linear variable displacement transducers (LVDTs). Deflection at mid-span was monitored using one LVDT (HBM W100TK $\pm 100 \mathrm{~mm}$, positioned so as to effect the reading near the neutral axis), while displacement at supports was measured using two LVDTs (HBM W20TK $\pm 20 \mathrm{~mm}$ ). Furthermore, strains were monitored at the mid-span of the beam throughout the depth and on the CFRP reinforcement by using strain gauges (TML PL$60-11,60 \mathrm{~mm}$ long). This was necessary so as to catch the degree of plasticization of the timber, as well as the shift in neutral axis due to compressive plasticization. Figure 3 shows a beam with strain gauges fixed on its lateral face (there are two more strain gauges at the top and at the bottom, which are not visible in this view). This strain gauge configuration was used for two of the Series A beams, three of the Series B beams and two of the Series $\mathrm{C}$ beams, while other beams had strain gauges only at the top and bottom sides. Strain data from strain gauges, deformation data from LVDTs and corresponding load data from the loading cell were all recorded by

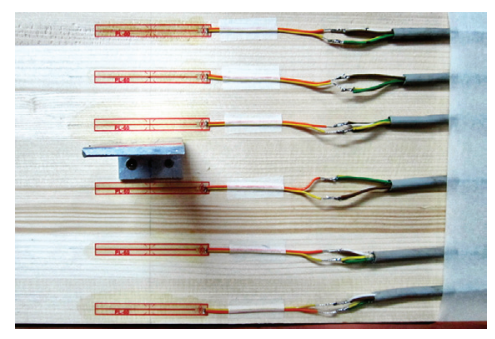

Fig. 3. Strain gauges arrangement 
using a computerized data acquisition (HBM MGC). Data acquisition was carried out with a frequency of $2 \mathrm{~Hz}$.

The monotonic static load was applied at a strokecontrolled rate of $4.5 \mathrm{kN}$ per minute so as to produce the failure of unreinforced glulam beams for approximately $10 \mathrm{~min}$. Reinforced beams were also tested by using the same load rate in order to ensure a fair comparison of test results. Time to failure for the reinforced beams was usually $10-15 \mathrm{~min}$. Before the tests had been carried out, the specimens were conditioned at the standard environment of relative humidity $65 \pm 5 \%$ and at the temperature of $20 \pm 2{ }^{\circ} \mathrm{C}$. Soon after the test had been completed, moisture content of a timber was measured with a digital hygrometer at different locations. The moisture content was in the range of $10.8-11.4 \%$ in all cases.

\section{Results and discussion}

\subsection{Load-deflection behaviour and failure mode}

The load-deflection behaviour to failure for the three groups of beams is shown in Figures 4-6.

Every unreinforced beam (Series A) failed within the elastic region due to a tension failure of the bottom laminations. Because of the timber's brittle nature when exposed to tension, most beams failed catastrophically without visible failures before reaching ultimate load. Once the timber showed signs of fissures, the cracks promptly developed and in some cases propagated along the timber grain, past the load application points and towards supports as seen in Figure 7(a). In four out of five specimens, the initial cracking of the timber initiated either at a defect or discontinuity (e.g. knots) in the tension zone, not very far from the mid-span (Fig. 7(b)). One beam failed in clear wood at the bottom lamination (Fig. 7(c)). There was no sign of compressive plasticization at the top lamination in any of unreinforced beams.

Experimental test carried out on reinforced beams, which are reinforced with one CFRP plate (Series B), demonstrated that the most frequent failure mechanism is the one in which tension failure occurs, with or without partial plasticization of the compression zone. As a comparison, the similar failure mode was obtained through the research done by Fiorelli and Dias (2011) for glulam specimens reinforced with glass FRP plates. Initially the load-deflection response is shown to be linear-elastic up to the local failure induced by presence of defect and discontinuity in the tension zone. Timber yield produced a non-linear response terminated by a sudden drop of the load as a result of timber rupture in the tension zone (Figs 7(d) trough 7(f)). The tough compression face displayed signs of plasticization in the form of a buckled fibre, but it remained intact. Results indicated that seven out of ten test beams failed at a knot in tension laminations, and two out of ten test beams failed at the bottom lamination due to clear wood tensile failure. Horizontal shear failure occurred in one beam. Sometimes the tension failure in the timber is explosive in nature, pushing off the composite layer as it develops (Fig. 7(f)). The

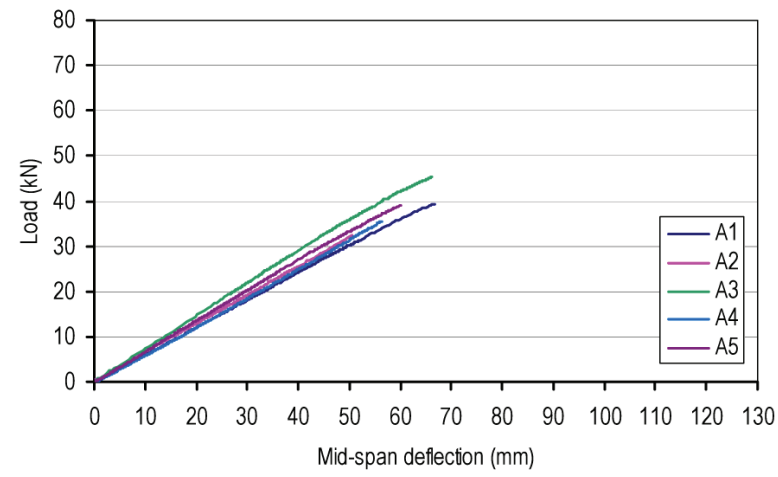

Fig. 4. Load-deflection behaviour for unreinforced beams (Series A)

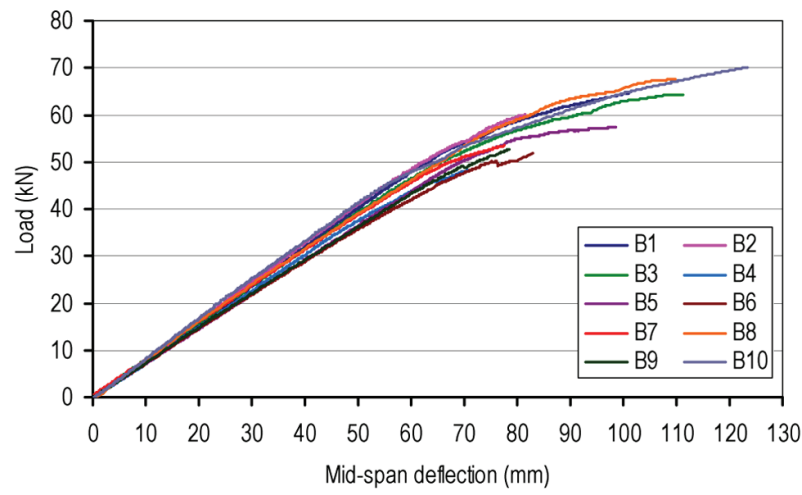

Fig. 5. Load-deflection behaviour for beams reinforced with one CFRP plate (Series B)

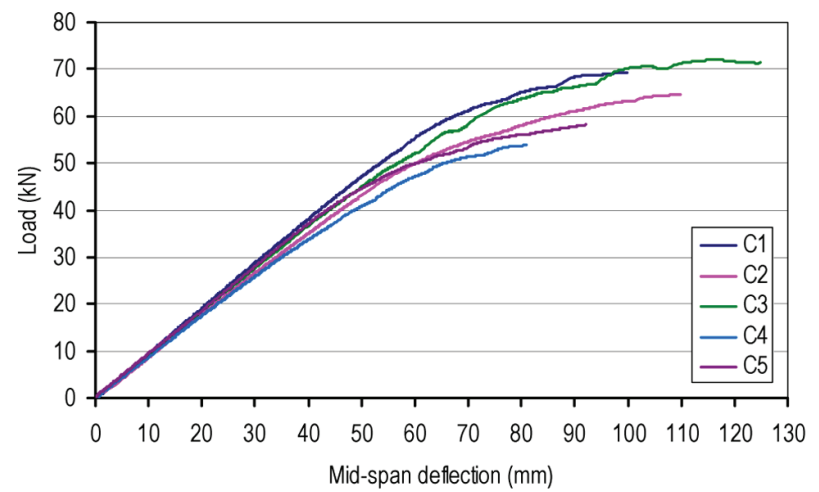

Fig. 6. Load-deflection behaviour for beams reinforced with two CFRP plates (Series C)

adhesion between timber and composite material failed only after timber rupture.

The beams reinforced with two CFRP plates (Series C) exhibited pseudo-ductile behaviour. Two types of failure mechanisms prevailed for the beams studied here: the timber fracture at the end of the bonded CFRP composites, caused by concentration of shear stresses in the anchorage zone, and timber longitudinal splitting, as shown in Figures 7(g) and 7(h). The ultimate shear failure was a consequence of a higher reinforcement ratio in the cross section. Higher reinforcement ratio at the cross section prevented normal bending failure and switched failure mode to shear failure, which was quite sudden and brittle. This phenomenon was also reported by Jacob and Bar- 

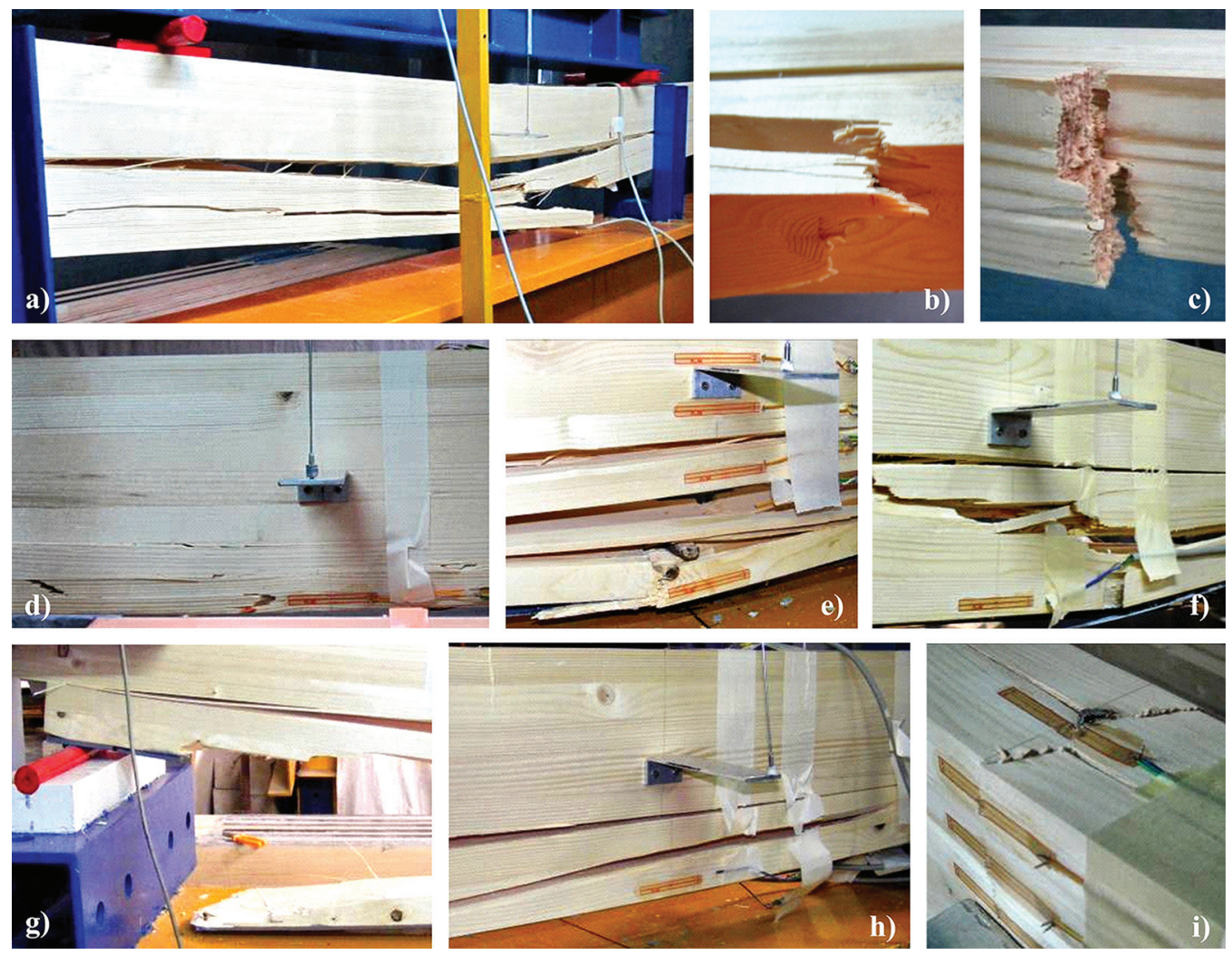

Fig. 7. Beam failure modes

ragan (2010). Compressive failure was observed in one of the specimens. Compressive plasticization was highly visible in the compression zone, with distinct crushing of timber (Fig. 7(i)). The bonds between CFRP reinforcement, timber and epoxy remained intact during a test.

In order to achieve more efficient use of CFRP reinforcement, the inclusion end-anchorage for the bonded CFRP plates to prevent premature shear failure becomes very much important. In this context, several anchorage schemes (clamps, anchor bolts, U-shaped straps, or wraps near the CFRP plate ends) can be applied and analysed so as to investigate their effect on the mode of failure and flexural capacity of reinforced beam. It is likely that improved shear capacity in the beams with two CFRP plates at the tension side would have resulted in more specimens having a principal failure mode in the compression zone.

The glulam beams reinforced with CFRP plates revealed more ductile behaviour when compared to unreinforced beams. The amount of ductile behaviour in the reinforced beams mostly depends on the quality of the bottom timber laminations (Raftery, Harte 2011). The CFRP composites act like bridges over the timber defects and make the structural member section more ductile.

\subsection{Ultimate load carrying capacity}

The ultimate load, maximum bending moment and deflection at a maximum load in terms of all beams are shown in Table 5.
The mean ultimate load of the control unreinforced specimens was $38.3 \mathrm{kN}$. The standard deviation was $6.6 \mathrm{kN}$; resulting in a coefficient of variation of $17.1 \%$. The large difference between the lowest and highest loads shows the large variability in the strength properties of a timber. Since timber is a natural material these results are expected and in design they are addressed by using only the 5th percentile strength and appropriate safety factors. If we can reduce this large variability, there is potential to make a design of timber less conservative in the future (Svecova, Eden 2004).

When making comparison with unreinforced beams, the reinforced ones failed at much higher loads. The tests carried out on ten specimens with one CFRP plate led to mean ultimate load of $59.1 \mathrm{kN}$, indicating a $54.3 \%$ increase over the control specimens. The mean ultimate load for the five specimens with two CFRP plates was $63.5 \mathrm{kN}$, indicating an increase of $65.8 \%$ over the control specimens. Furthermore, a lower coefficient of variation of approximately $12 \%$ is associated with the reinforced beams when compared to $17 \%$ in terms of unreinforced beams. This suggests that a reduction in variability of the ultimate load capacity of beams occur by bonding CFRP plate at the tension side.

The load carrying capacity enhancement was not proportional to the amount of reinforcement. The load carrying capacity was enhanced only by cca $20 \%$ when the reinforcement ratio was increased twofold (from $0.46 \%$ to $0.93 \%$ ). This phenomenon may be explained by the fact that over-reinforcing a glulam member in flexure results in a shear dominated failure. 
Table 5. Experimental results from bending tests

\begin{tabular}{|c|c|c|c|c|c|}
\hline Series & Specimen & Maximum load (kN) & $\begin{array}{l}\text { Mid-span deflection at } \\
\text { maximum load (mm) }\end{array}$ & $\begin{array}{l}\text { Maximum bending } \\
\text { moment }(\mathrm{kNm})\end{array}$ & $\begin{array}{l}\text { Bending stiffness EI } \\
\qquad\left(\times 10^{11} \mathrm{Nmm}^{2}\right)\end{array}$ \\
\hline \multirow{8}{*}{ A } & A1 & 39.4 & 66.7 & 24.8 & 6.06 \\
\hline & $\mathrm{A} 2$ & 32.3 & 50.5 & 20.3 & 6.43 \\
\hline & A3 & 45.4 & 66.3 & 28.6 & 7.29 \\
\hline & A4 & 35.5 & 56.5 & 22.4 & 6.18 \\
\hline & A5 & 39.0 & 60.1 & 24.6 & 6.76 \\
\hline & Mean & 38.3 & 60.0 & 24.1 & 6.54 \\
\hline & St. Dev & 6.6 & 9.3 & 4.1 & 0.63 \\
\hline & $\mathrm{CoV}(\%)$ & 17.1 & 15.4 & 17.1 & 9.6 \\
\hline \multirow{13}{*}{$\mathrm{B}$} & B1 & 64.6 & 100.9 & 40.7 & 7.97 \\
\hline & B2 & 60.0 & 81.5 & 37.8 & 8.18 \\
\hline & B3 & 64.4 & 111.2 & 40.6 & 7.78 \\
\hline & B4 & 48.4 & 71.0 & 30.5 & 7.53 \\
\hline & B5 & 57.3 & 98.5 & 36.1 & 7.32 \\
\hline & B6 & 51.8 & 83.0 & 32.6 & 7.20 \\
\hline & B7 & 53.4 & 77.6 & 33.7 & 7.85 \\
\hline & B8 & 67.5 & 109.7 & 42.5 & 7.82 \\
\hline & B9 & 53.7 & 80.8 & 33.9 & 7.30 \\
\hline & $\mathrm{B} 10$ & 70.1 & 123.5 & 44.2 & 8.31 \\
\hline & Mean & 59.1 & 93.8 & 37.2 & 7.73 \\
\hline & St. Dev & 7.3 & 17.4 & 4.6 & 0.38 \\
\hline & $\mathrm{CoV}(\%)$ & 12.4 & 18.6 & 12.4 & 4.9 \\
\hline \multirow{8}{*}{$\mathrm{C}$} & $\mathrm{C} 1$ & 69.3 & 99.8 & 43.7 & 9.58 \\
\hline & $\mathrm{C} 2$ & 64.6 & 109.7 & 40.7 & 8.83 \\
\hline & $\mathrm{C} 3$ & 72.0 & 115.5 & 45.3 & 9.17 \\
\hline & $\mathrm{C} 4$ & 53.8 & 81.0 & 33.9 & 8.61 \\
\hline & $\mathrm{C} 5$ & 58.2 & 92.2 & 36.6 & 9.35 \\
\hline & Mean & 63.5 & 99.6 & 40.0 & 9.11 \\
\hline & St. Dev & 7.6 & 13.8 & 4.8 & 0.39 \\
\hline & $\mathrm{CoV}(\%)$ & 11.9 & 13.8 & 11.9 & 4.3 \\
\hline
\end{tabular}

The results with regard to load carrying capacity are in reasonable agreement with the results obtained by other researchers (Blaß, Romani 2000; Gilfillan et al. 2003; Issa, Kmeid 2005) where the ultimate load was increased by $35-70 \%$ when glulam beams were reinforced using CFRP plates for reinforcement ratio between $0.4-1.2 \%$. As a comparison, the research done by Raftery and Harte (2011) on use of glass FRP plates to reinforce the glulam beams showed an mean increase in ultimate load capacity of $38 \%$ with respect to unreinforced beams in case of $1.26 \%$ cross-sectional reinforcement. The reinforcement effect increases with increasing reinforcement ratio and with increasing modulus of elasticity of reinforcement. Also, the effect of reinforcing is more pronounced in timber of lower grade.

CFRP reinforced beams underwent large deformation before the failure. The reinforced beams of Series B and Series C showed an increase of $56.2 \%$ and $66.0 \%$ in their mid-span deflection at the maximum load, respectively, when compared to the unreinforced beams (Series A).

\subsection{Stiffness}

For load-deflection curves shown in Figures 4-6, the elastic region up to half the failure load was considered to determine the stiffness for each beam. Linear regression analysis for that region was carried out to calculate the gradient of the slope. The results of bending stiffness for the unreinforced and reinforced glulam beams are shown in Table 5.

Unreinforced beams had a mean stiffness of $6.54 \times 10^{11} \mathrm{Nmm}^{2}$ with a coefficient of variation of $9.6 \%$. The mean stiffness of Series B beams was $7.73 \times 10^{11} \mathrm{Nmm}^{2}$ with coefficient of variation of $4.9 \%$, while the mean stiffness of Series $\mathrm{C}$ beams was $9.11 \times 10^{11} \mathrm{Nmm}^{2}$ whose coefficient of variation was $4.3 \%$. The increase in stiffness was $18.1 \%$ and $39.2 \%$ with respect to unreinforced beams, respectively, in case of one or two CFRP plates. In general, the stiffness enhancement was proportional to the amount of reinforcement.

The results concerning the stiffness are in good agreement with the results reported by others (Blaß, 
Romani 2000; Gilfillan et al. 2003; Issa, Kmeid 2005) where the increase of stiffness varied from 15 to $55 \%$ for beams reinforced with CFRP plates. As a comparison, Raftery and Harte (2011) found that the stiffness for glulam beams reinforced with glass FRP plates was increased by $13 \%$ with respect to the unreinforced beams.

The introduction of stiffer material at the cross section resulted in increased stiffness of the beams, which in turn resulted in lesser deflection. This low deflection phenomenon is desirable from the point of view of serviceability limit state so as to ensure comfort of timber structures (Yusof 2010).

\subsection{Strain distribution}

For each of the beams, the strain in timber and CFRP plate was monitored at a mid-span by using strain gauges, as previously described. All strains were measured during the test, but a continuous record of strain was not always possible. Either cracking or crushing of beams sometimes caused damage to gauges and prevented further measurement of the strain. The typical strain profiles of unreinforced and reinforced glulam beams are shown at different load levels in Figures 8-10. These profiles report compressive and tensile strains as negative and positive values at the $\mathrm{x}$-axis, respectively, and the strain gauge locations at the y-axis corresponding to the compression and tension zone of the cross section.

The tensile and compressive stains were symmetric for the unreinforced beams. The strain distribution across the cross section was quite linear until failure, confirming the assumption from the bending theory that plane sections remain plane during bending.

Linear strain distribution over the specimen depth could be observed in the elastic range for reinforced beams. A non-linear strain distribution nearby the state of failure could be observed in reinforced beams where plastic behavior in the compression zone was reached. For beams reinforced with two CFRP plates, the nonlinear behavior of the compressed wood is more evident, with strain values that are lower in the compression zone. Due to the contribution of the additional CFRP tension element, the neutral axis is shifted towards the tension face of the beam. The neutral axis was placed at approximately 7 and $15 \mathrm{~mm}$ below the cross section mid-height of one and two CFRP plates reinforced beams, respectively. No distinct variation of the neutral axis depth of the reinforced beams was found between the elastic and ultimate behaviour states. The strain measured on CFRP plates fits very well with the strain measured in the glulam. This indicates that there is no appreciable slip between the timber and reinforcing CFRP material.

The reinforced beams exhibited a noticeable improvement of strains in timber. For example, the tension strains of Beam B1 and Beam C1 were $87 \%$ and $70 \%$, respectively, of the strain of Beam A3 at an applied load of $45.4 \mathrm{kN}$ (failure load of Beam A3). The CFRP reinforcement overcomes the impact of a local defect in

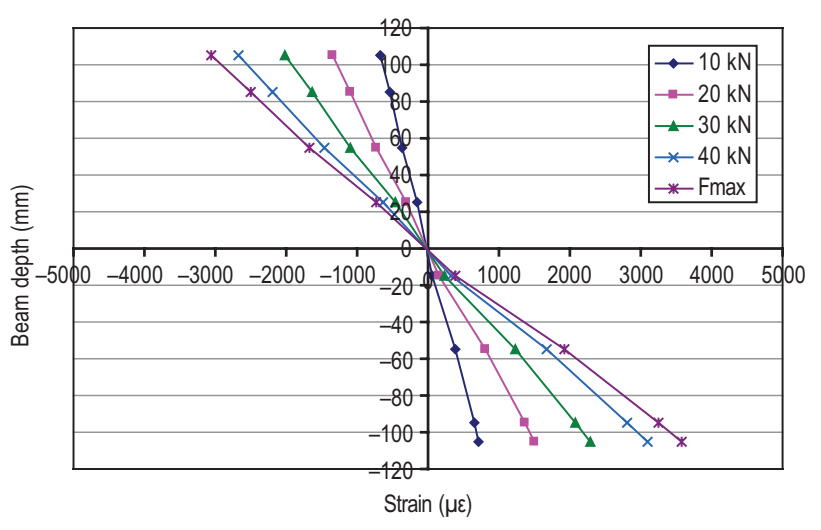

Fig. 8. Strain profile at different load levels for unreinforced beams (Beam A3)

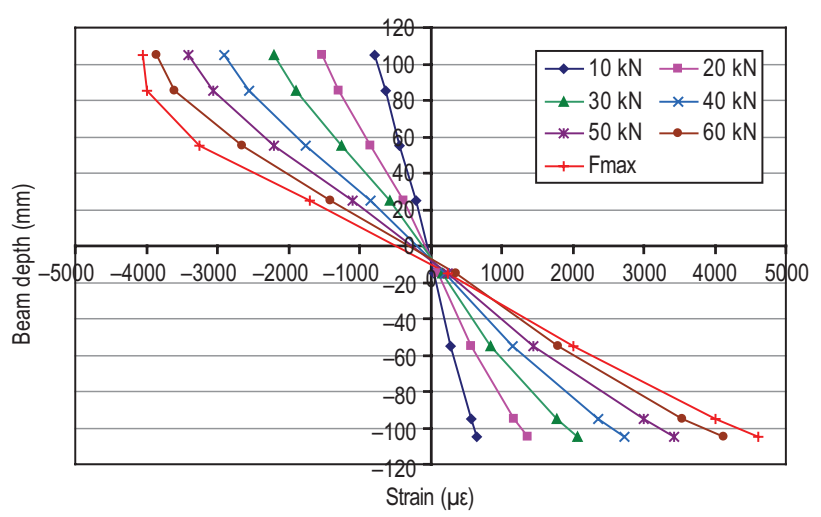

Fig. 9. Strain profile at different load levels for beams reinforced with one CFRP plate (Beam B1)

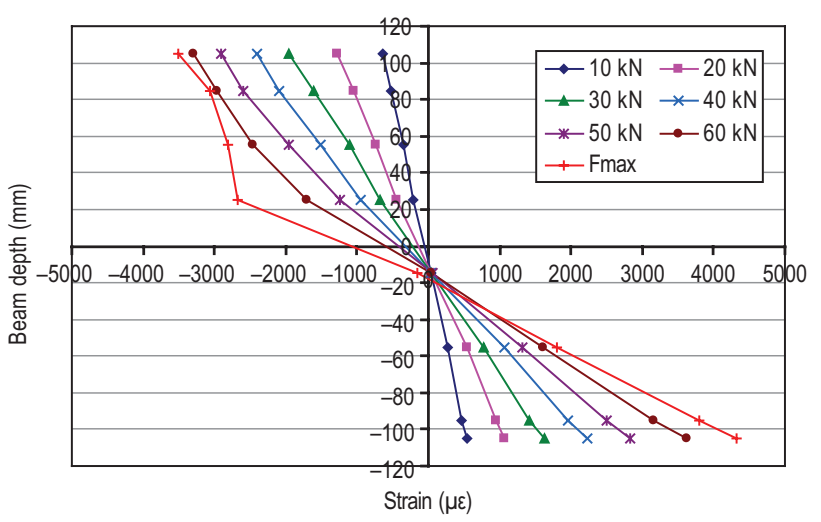

Fig. 10. Strain profile at different load levels for beams reinforced with two CFRP plates (Beam $\mathrm{C} 1$ )

the timber resulting in the increase of the ultimate timber tensile strain. Moreover, this reinforcement allows for greater strain in the compression region owing to the greater distance of timber compression fibres from the neutral axis.

In all reinforced beams, tensile stresses in the CFRP reinforcement at an onset of beam failure remained well below ultimate strength. Table 6 summarizes the average tensile strains and stresses in the CFRP reinforcement at failure for reinforced beams. The tensile stresses were calculated using data obtained from strain gauges and 
value of elasticity modulus of the CFRP plate. The average tensile stress at failure in CFRP plate for beams with a reinforcement ratio of $0.46 \%$ was $729 \mathrm{MPa}$, or about $26 \%$ of ultimate strength, while the same parameter was equal to $785 \mathrm{MPa}$ for beams with a reinforcement ratio of $0.93 \%$, or about $28 \%$ of the ultimate strength. This showed the reinforcement's effectiveness in terms of exploitation of the CFRP material.

Table 6. Average values of tensile strain and stress in CFRP reinforcement at failure

\begin{tabular}{cccc}
\hline Series & $\begin{array}{c}\text { Reinforcement } \\
\text { ratio (\%) }\end{array}$ & $\begin{array}{c}\text { Tensile } \\
\text { strain (\%) }\end{array}$ & $\begin{array}{c}\text { Tensile } \\
\text { stress (MPa) }\end{array}$ \\
\hline $\mathrm{B}$ & 0.46 & 0.442 & 729 \\
\hline $\mathrm{C}$ & 0.93 & 0.476 & 785 \\
\hline
\end{tabular}

\section{Conclusions}

Experimental program was conducted in order to investigate the effectiveness of CFRP plates as flexural reinforcement of glulam beams. Two different amounts of CFRP reinforcement were used at the tension side of the glulam section. The bending behaviour of the beams was studied both through their load-deflection characteristics and failure mode. Strain distribution across the depth of the beam upon loading was studied as well.

The unreinforced glulam beams demonstrated linear elastic behaviour and exhibited brittle tensile-flexural failures when compared to pseudo-ductile behaviour of the reinforced beams. The reinforcing influences the plastic behaviour of the beam, which otherwise is not so predominant due to the low tensile strength of the timber. The rupture of the CFRP reinforced glulam beams was always reached due to the crisis of the timber. No bond failure was observed for reinforced beams although a secondary debonding failure of the CFRP occurred in some cases due to push-off of the split timber near midspan.

The CFRP attached at the tensile side of glulam beams resulted in moderate enhancements in the stiffness, while more significant improvements were obtained in the ultimate load capacity. The amount of reinforcement in the cross section is very important in terms of strength, stiffness and failure modes. The increase in stiffness is obvious as the increasing area of reinforcement basically means introducing stiffer material to the cross section. On the other hand, it can be seen that increase in reinforcement may not necessarily result in increase in strength properties, as the shear failure mode becomes prominent for higher reinforced beams.

Strategically positioned, the CFRP reinforcement in the more highly stressed tension region at the bottom of the beam allows for timber compression fibres to reach their yield strains and, hence, better utilization of the compressive properties of the timber.

The experiments show that the introduction of CFRP reinforcement in the cross section reduces the variability in results. The reinforced specimens were more consistent in their properties and behaviour. This indicates the ability of the CFRP material to reduce the effect of natural defects in timber.

According to current results, it is possible to conclude that the application of externally bonded CFRP plates is a promising solution to reinforce (repair) the glulam beams. Further research is necessary to examine the influence of using different material properties (of timber, reinforcements as well as adhesives) and different geometries on the strength and stiffness of glulam beams for both the serviceability and ultimate limit states. Another point that needs to be further studied is the longterm reliability, especially when considering bond properties, and also the behaviour of reinforced beams under cyclic and dynamic loads. Moreover, further research is needed so as to establish a realistic strength model and design procedure that can be applied extensively in engineering design.

\section{References}

ACI 440.2R-08 Guide for the design and construction of externally bonded FRP systems foe strengthening concrete structures. American Concrete Institute, Farmington Hills, Mich, USA, 2008.

Andre, A. 2006. Fibres for strengthening of timber structures. Research report. Department of Civil and Enviromental Engineering, Lulea University of Technology, Lulea, Sweden.

Borri, A.; Corradi, M.; Grazini, A. 2005. A method for flexural reinforcement of old wood beams with CFRP materials, Composites: Part B 36: 143-153.

http://dx.doi.org/10.1016/j.compositesb.2004.04.013

Blaß, H. J.; Romani, M. 2000. Trag- und Verformungsverhalten von Verbundträgern aus Brettschichtholz und faserverstärkten Kunststoffen. Forschungsbericht der Versuchsanstalt für Stahl, Holz und Steine, Abt. Ingenieurholzbau der Universität Karlsruhe (in German).

EN 338:2009 Structural timber - Strength classes. European Committee for Standardization, Brussels, Belgium, 2009.

EN 408:2010 Timber structures - Structural timber and glued laminated timber - Determination of some physical and mechanical properties. European Committee for Standardization, Brussels, Belgium, 2010.

EN ISO 527-5:2009 Plastics - Determination of tensile properties - Part 5: Test conditions for unidirectional fibrereinforced plastic composites. European Committee for Standardization, Brussels, Belgium, 2009.

Fiorelli, J.; Dias, A. A. 2003. Analysis of the strength and stiffness of timber beams reinforced with carbon fiber and glass fiber, Materials Research 6(2): 193-202. http://dx.doi.org/10.1590/S1516-14392003000200014

Fiorelli, J.; Dias, A. A. 2006. Fiberglass-reinforced glulam beams: mechanical properties and theoretical model, $M a$ terials Research 9(3): 263-269. http://dx.doi.org/10.1590/S1516-14392006000300004

Fiorelli, J.; Dias, A. A. 2011. Glulam beams reinforced with FRP externally-bonded: theoretical and experimental evaluation, Materials and Structures 44: 1431-1440. http://dx.doi.org/10.1617/s11527-011-9708-y

Gentile, C. 2000. Flexural strengthening of timber bridge using FRP. MSc Thesis. Department of Civil and Geological Engineering, University of Manitoba, Winnipeg, Manitoba, Canada. 
Gilfillan, R. J.; Gilbert, S. G.; Patrick, G. R. H. 2003. The use of FRP composites in enhancing the structural behaviour of timber beams, Journal of Reinforced Plastics and Composites 22(15): 1373-1388. http://dx.doi.org/10.1177/073168403035583

Hernandez, R.; Davalos, J. F.; Sonti, S. S.; Kim, Y.; Moody, R. C. 1997. Strength and stiffness of reinforced yellow-poplar glued-laminated beams. Res. Pap. FPLRP-554, U. S. Department of Agriculture, Forest Service, Forest Products Laboratory, Madison, WI. 28 p.

Issa, C. A.; Kmeid, Z. 2005. Advanced wood engineering: glulam beams, Construction and Building Materials 19: 99106. http://dx.doi.org/10.1016/j.conbuildmat.2004.05.013

Jacob, J.; Barragan; O. L. G. 2010. Flexural strengthening of glued laminated timber beams with steel and carbon fiber reinforced polymers. MSc Thesis. Department of Civil and Enviromental Engineering, Chalmers University of Technology, Göteborg, Sweden.

Jankowski, L. J.; Jasienko, J.; Nowak, T. P. 2010. Experimental assessment of CFRP beams by 4-point bending tests and photoelastic coating technique, Materials and Structures 43: 141-150. http://dx.doi.org/10.1617/s11527-009-9476-0

Johns, K. C.; Lacroix, S. 2000. Composite reinforcement of timber in bending, Canadian Journal of Civil Engineering 27(5): 899-906. http://dx.doi.org/10.1139/I00-017

Juvandes, L. F. P.; Barbosa, R. M. T. 2012. Bond analysis of timber structures strengthened with FRP systems, Strain 48: 124-135.

http://dx.doi.org/10.1111/j.1475-1305.2011.00804.x

Li, Y. F.; Xie, Y. M.; Tsai, M. J. 2009. Enhancement of the flexural performance of retrofitted wood beams using CFRP composite sheets, Construction and Building Materials 23: 411-422.

http://dx.doi.org/10.1016/j.conbuildmat.2007.11.005
Raftery, G. M.; Harte, A. M. 2011. Low-grade glued laminated timber reinforced with FRP plate, Composites: Part B 42: 724-735. http://dx.doi.org/10.1016/j.compositesb.2011.01.029

Raftery, G. M.; Harte, A. M.; Rodd, P. D. 2009. Bonding of FRP materials to wood using thin epoxy gluelines, International Journal of Adhesion and Adhesives 29: 580-588. http://dx.doi.org/10.1016/j.ijadhadh.2009.01.004

Schober, K. U.; Rautenstrauch, K. 2006. Post-strengthening of timber structures with CFRP's, Materials and Structures 40: 27-35. http://dx.doi.org/10.1617/s11527-006-9128-6

Sika Group. 2011a. Sika CarboDur Plates. Pultruded carbon fibre plates for strengthening. Product data sheet [online], [cited 4 May 2011]. Available from Internet: www.sika.com

Sika Group. 2011b. Sikadur-30. Adhesive for bonding reinforcement. Product data sheet [online], [cited 5 May 2011]. Available from Internet: www.sika.com

Svecova, D.; Eden, R. J. 2004. Flexural and shear strengthening of timber beams using glass fibre reinforced polymer bars - an experimental investigation, Canadian Journal of Civil Engineering 31(1): 45-55. http://dx.doi.org/10.1139/L03-069

Yahyaei-Moayyed, M.; Taheri, F. 2011. Experimental and computational investigations into creep response of AFRP reinforced timber beams, Composite Structures 93: 616628. http://dx.doi.org/10.1016/j.compstruct.2010.08.017

Yusof, A. 2010. Bending behavior of timber beams strengthened using fiber reinforced polymer bars and plates. $\mathrm{PhD}$ thesis. Faculty of Civil Engineering. Universiti Teknologi Malaysia, Skudai, Malaysia.

Ivan GLIŠOVIĆ. Assistant Professor at the Chair of Materials and Structures, Faculty of Civil Engineering, University of Belgrade. Field of research: timber and masonry structures.

Boško STEVANOVIĆ. Full Professor, Director of the Institute of Materials and Structures, Faculty of Civil Engineering, University of Belgrade. Field of research: timber, composite timber-concrete and masonry structures.

Miloš PETROVIĆ. PhD student, Teaching Assistant at the Chair of Materials and Structures, Faculty of Civil Engineering, University of Belgrade. Field of research: timber and masonry structures. 